\title{
EUCLIDES DA CUNHA E O BICENTENÁRIO DA IMPRENSA
}

\section{EUCLIDES OF THE WEDGE AND THE BICENTENÁRIO OF THE PRESS}

\author{
Licia de Sousa*
}

RESUMO: Este artigo busca mostrar as contribuições de Euclides da Cunha para a literatura contemporânea e para a imprensa do século $\mathrm{XX}$. Inscrevendo-se na tendência da militância política que norteava a escrita jornalística até a primeira guerra mundial, Euclides se firmou como um articulista hábil para cobrir a guerra de Canudos. Descobrindo um Brasil profundo, nos sertões, diferente do que imaginava o Brasil civilizado, o jornalista escreveu o livro Os sertões que contém uma teoria da comunicação, aliada a uma teoria da formação da opinião pública, que mostra uma língua portuguesa viva, relacionada com as ciências naturais, a cultura sertaneja, as táticas de guerra, as novas tecnologias, e a história do Brasil.

PALAVRAS-CHAVE: Literatura brasileira, imprensa, teoria da comunicação, opinião pública.

ABSTRACTS: This article looks for showing the contributions of Euclides da cunha for the contemporary literature and for the press of the century XX. Being registered in the tendency of the political militancy that was orientating the journalistic writing up to the first world war, Euclides was based like a clever newspaper writer to cover the war of Canudos. Discovering a Brazil, in the backwoods, differently from what was imagining as a civilized Brazil, the journalist wrote the book Os Sertões what there contains a theory of the communication, allied to a theory of the formation of the public opinion, which shows a Portuguese lively language connected with the natural sciences, the culture from the backwoods, the tactics of war, the new technologies, and the history of Brazil.

KEY WORDS: Brazilian literature, press, theory of the communication, public opinion

\footnotetext{
* Licia Soares de Sousa (Universidade Estadual da Bahia)
} 



\section{EUCLIDES DA CUNHA E O BICENTENÁRIO DA IMPRENSA}

\section{Considerações Preliminares}

São inúmeras as atividades, colóquios e publicações que assinalam a instauração da Imprensa Régia, em 1808, com a chegada do príncipe regente D. João $\mathrm{VI}^{1}$. Antes, escritos que apareciam na colônia deveriam ser publicados na Europa ou permanecer na forma de manuscrito, uma regra atribuída ao Marquês de Pombal que temia o poder dos jesuítas.

Nessas comemorações, muitos jornalistas e editores são lembrados e não podemos deixar de pensar também nas atividades de Euclides da Cunha, como um dos maiores jornalistas do país que se tornou um dos pilares da cultura nacional. A revisão da República é uma temática essencial na obra deste autor, presente nos artigos que escreveu para jornais de São Paulo ou do Rio de Janeiro de 1888 a 1892. Mas ele cessa de militar pelo novo regime, exprimindo uma descrença em seus novos rumos após a cobertura da guerra de Canudos.

No livro Os sertões (1902), existe não apenas uma crítica à República e ao exército, mas fundamentalmente uma crítica às apropriações das atividades comunicacionais da época com certas manobras de manipulação da opinião nacional. Essa segunda crítica é importante na fatura

1 Em janeiro de 1808, D. João aportou na Bahia, onde assinou uma Carta Régia abrindo os portos brasileiros ao comércio com as nações amigas. No mês seguinte, ele e sua Corte partiram em direção ao Rio de Janeiro, aonde chegaram a 7 de março. Na Bahia, D. João abriu a primeira Faculdade de Medicina do país. 
pluriperspectivista de Os sertões, pois, com as variadas máscaras de narrador que ele assume, emerge uma metalinguagem, instaurando um debate sobre o exercício dos jornalistas da época, que aproxima a narrativa das contemporâneas onde o diálogo entre ficção e meios de comunicação marca a feição atual da literatura brasileira.

Como o diz Roberto Ventura (cf. biblio.), Euclides comemorou, em $1^{\circ}$ de janeiro de 1889, a chegada do novo ano com um artigo intitulado "89". Ele comparava 1789, ano da Revolução Francesa, à 1889, fazendo paralelos entre a revolução política francesa e o movimento republicano no Brasil. A revolução francesa, ressalta ainda Ventura, sempre esteve presente no imaginário dos republicanos brasileiros ao ponto de jornais, como a $\mathrm{Ga}$ zeta de Notícias e A Província de S. Paulo, publicarem, em 1889, narrativas de episódios da Queda da Bastilha, extraídas de obras de Taine, Michelet e Aulard. O aniversário da derrocada do Antigo Regime era celebrado, no Rio e em São Paulo, com passeatas ao som da Marselhesa, que era a canção revolucionária favorita dos cadetes da Escola Militar. Mas essa formação imaginária e discursiva, em torno da revolução francesa, teve conseqüências trágicas no momento da guerra de Canudos, à medida que o governo, o exército e o próprio Euclides da Cunha acreditaram que estavam lutando contra revoltosos anti-republicanos que desejavam a restauração monárquica.

Em março de 1897, Euclides publica em O Estado de São Paulo, dois artigos com o título A nossa Vendéia, mostrando que, nos confins da Bahia, havia uma sublevação monarquista e católica, aparentada a que havia ocorrido na Vendéia:

A mesma coragem bárbara e singular e o mesmo terreno impraticável aliam-se, completam-se. O chouan fervorosamente crente ou o tabaréu fanático, precipitando-se impávido à boca dos canhões que tomam o pulso, patenteiam o mesmo heroísmo mórbido difundido numa agitação desordenada e impulsiva de hipnotizados.

A justeza do paralelo estende-se aos próprios revezes sofridos. A Revolução Francesa que se aparelhava para lutar com a Europa, quase sentiu-se impotente para combater os adversários impalpáveis da Vendéia - heróis intangíveis que se escoando céleres através das charnecas prendiam as forças republicanas em inextricável rede de ciladas... ( Nossa Vendéia I, O Estado de São Paulo, julho de 1897). 
O jornalista compara o tabaréu ao chouan ${ }^{2}$ fanático que luta de forma intempestiva sem racionalidade com uma espécie de heroísmo equivocado. É o heroísmo das guerrilhas, que ficou conhecido como tal nos anos 1960, mas que, no século XIX, foi descrito por Victor Hugo e Balzac como a guerra das emboscadas e dos labirintos que desorientava qualquer pelotão organizado de exército. A bravura dos chouans contava com a forte aliada, a natureza, que o protegia e o amparava exatamente como a caatinga o fazia com os sertanejos turbulentos. E a comparação parecia garantir uma certeza de vitória sobre os conselheristas, pela crença na repetição da história. Ela garante ao jornalista o prêmio de ir cobrir a guerra, lá onde ele vai refletir sobre seu próprio exercício de formador de opinião e mostrar que o sertanejo não possuía nenhuma convicção política, nem republicana, nem monarquista, estava lutando apenas para defender o "lar invadido".

O escritor Oleone Coelho Fontes ${ }^{3}$, em artigo no Suplemento Cultural do jornal A Tarde, de 6 de outubro de 2007, relata como Euclides da Cunha, ao chegar em Salvador, busca as redações dos principais jornais (Diário da Bahia, Diário de Notícias, Jornal de Notícias e Correio de Notícias), para expor o duplo objetivo de sua viagem. O primeiro era o de enviar relatos da guerra para o diário paulista e o segundo era relativo ao recolhimento de material geológico da região convulsionada para candidatar-se à cadeira de Geologia da Escola Politécnica de São Paulo. A Terra, primeira parte de Os sertões, exibe não apenas o conhecimento científico da geologia, como promove um texto emblemático do consórcio entre arte e ciência, onde o narrador inaugura uma geopoética ${ }^{4}$ capaz de estetizar as ciências naturais.

Euclides trazia uma carta de apresentação de Campos Salles para o governador da Bahia, o conselheiro Luiz Viana. Para a entrega desta correspondência, o jovem repórter entrou em contacto com autoridades militares e com um médico, oficial da polícia, o major Edgard Henrique Albertazzi ${ }^{5}$, que havia estado na Expedição Febrônio de Brito. As experiências contadas pelo médico levam Euclides a montar o capítulo Travessia do Cambaio. Nele, o

2 O chefe deles se chamava Jean Chouan.

Autor do romance $A 5^{a}$. expedição, 2002.

4 Vide SOUZA, A geopoética de Euclides da Cunha, 2002.

5 Segundo Oleone Fontes, esse encontro se encontra nas memórias manuscritas de Albertazzi ainda não publicadas. 
autor mostra uma simpatia por Febrônio de Brito, que não é a mesma demonstrada pelo Tenente Pires de Ferreira chefe da primeira expedição, cuja descrição é transcrita dos jornais, principalmente do Jornal de Notícias.

Em Salvador, Euclides entrevistou muitos soldados que retornavam feridos das batalhas e ouviu na estação da estrada de ferro da Calçada, Cláudio do Amaral Savaget, comandante da segunda coluna, denominada Talentosa, e Carlos Telles, outro oficial superior do exército ${ }^{6}$. É bem verdade que os artigos do jovem repórter foram censurados, assim como o livro Os sertões, o que levou o autor a prolongar as primeiras partes, A Terra e O Homem, antes de abordar a campanha de Canudos. Como o assinala Fontes, é interessante a coincidência de experiências entre Euclides e o jovem estudante de medicina Alvim Martins Horcades, contratado igualmente como correspondente de guerra para o jornal de Notícias. No seu livro Descrição a uma viagem a Canudos, publicado antes do de Euclides, ele declara haver nele incluído artigos não publicados nos jornais que foram censurados. Ambos seguiram assim um mesmo trajeto, buscando a via do livro para tornarem público suas atividades jornalísticas não autorizadas pelos arautos da censura. Após a publicação de sua obra, em dezembro de 1902, Euclides foi exilado para o Amazonas, um destino semelhante ao do jovem poeta Francisco Mangabeira que publicou a Tragédia Épica (Guerra de Canudos), em 1900, segundo registra Fontes.

\section{O argumento próprio para a repressão}

Registrando, desde o início da campanha de Canudos, a natureza das desordens relativas às populações interioranas perdidas e as dificuldades das multidões urbanas a compreender o novo regime democrático, o que parecia caracterizar uma associação d e alienados, no encontro com os sertões de Canudos, Euclides determinou o estabelecimento de uma opinião nacional a partir de componentes mais emocionais do que cognitivos e foi assim criticando o argumento repetido para condenar os jagunços:

A República estava em perigo. Era preciso salvar a República... (CUNHA, 200, p. 314).

\footnotetext{
${ }^{6}$ É sabido que Euclides esteve no local da guerra durante apenas sete dias.
} 
E é o próprio autor quem traz o contra-argumento, mesmo já os tendo caracterizado como chouans de nossa Vendéia.

Atribuir a uma conspiração política qualquer a crise sertaneja, exprimia palmar insciência das condições naturais de nossa raça... (CUNHA, ibid., p. 316).

Vejamos que o termo insciência configura a formação de uma matriz de opinião, por um coletivo social, que, exposto à ação dos meios de comunicação, as vozes mediáticas, e ativando uma série de discursos anteriores heterogêneos, construía uma generalização ilógica em torno da crise sertaneja. Nesse caso, são os rudes patrícios retardatários, abandonados em trezentos anos nos sertões que agiam dentro da mais perfeita lógica, esses rudes que encarnam uma espécie de homem-outro que a nação não conhecia.

Insulado no espaço e no tempo, o jagunço, um anacronismo étnico, só podia fazer o que fez - bater, bater terrivelmente a nacionalidade que, depois de o enjeitar, cerca de três séculos, procurava levá-lo para os deslumbramentos da nossa idade dentro de um quadrado de baionetas, mostrando-lhe o brilho da civilização através do clarão de descargas (CUNHA, ibid., p. 310).

Os jagunços que já foram caracterizados como os titãs, que transformam o espaço dimensional natural em zonas de fontes de vida e de proteção, aparecem, nesse momento, como simples defensores de um lar construído que abrigava os excluídos da sociedade brasileira. E o escritor faz uma crítica à falta de raciocínio lógico do lado civilizado, o litoral comparado a uma Suíça industrial. Pois, se esses civilizados dispusessem de critérios racionais, a descoberta das diferenças regionais não levaria ao massacre, e sim ao conhecimento das populações sertanejas abandonadas, o que proporcionaria um ensinamento fundamental da nossa história e trocas benéficas do progresso.

Sob tal aspecto era, antes de tudo m ensinamento e poderia ter despertado uma grande curiosidade (...) Entre nós, de m modo geral, despertou rancores. Não vimos o traço superior do acontecimento. Aquele afloramento originalíssimo do passado, patenteando todas as falhas da nossa evolução, era um belo ensejo para estudarmolas, corrigirmo-las ou anularmo-las. Não entendemos a lição eloqüente. 
Na primeira cidade da República, os patriotas satisfizeram-se com o auto de fé de alguns jornais adversos e o governo começou a agir. Agir era isso - agremiar batalhões. (CUNHA, ibid, p. 314).

Mas uma grande inovação da obra euclidiana é, sem sombra de dúvida, a formação do estatuto do narrador que se apresenta com várias máscaras ${ }^{7}$. Como observador itinerante, a descrição do planalto central do Brasil se converte em narração pela interação de dois mediadores: o narrador que mobiliza a consciência a fim de assegurar a coerência estrutural da obra e que acompanha o observador deslumbrado que transmite ao leitor o impacto emocional de sua experiência imediatamente vivida. Como pintor de quadros da natureza, o narrador representa o drama da terra, apropriando-se do princípio de composição da elaboração artística das narrativas de viagem de Alexander von Humboldt, com quem ele empreende um diálogo intertextual, que estipula o consórcio da ciência e da arte.

Com mais duas outras máscaras essenciais, Euclides pôde deixar sua herança, tanto para a literatura como para a imprensa juntando-as em sua metalinguagem crítica. Uma dessas máscaras é a que Renaldes Souza caracteriza como a do refletor dramático que se apresenta tomado pelas emoções trágicas que Aristóteles chama de éleos, a compaixão, e o pholos, o terror, com as quais fala do martírio da terra e dos efeitos catastróficos da cidade morta, massacrada pelo exército. Ao representar o efeito trágico da guerra, e não a guerra em si mesma, o refletor dramático se apropria do procedimento artístico da tragédia grega, e acentua para seus leitores as conseqüências para a jovem República de um massacre fratricida dessa dimensão.

E a outra máscara é a do historiador irônico que tem a função de questionar os preconceitos nacionais acerca da formação do povo brasileiro e da guerra de Canudos. Segundo os pressupostos da elucidação meta-histórica de Hayden White (1973), Ronaldes Souza demonstra como Euclides realiza um ato essencialmente poético, encarando a história pelo questionamento das vozes oficiais, e adotando o ponto de vista dos vencidos, emocionalmente sintonizado com os bárbaros canudenses. Nesse âmbito, o autor empreende uma discussão metalingüística, a partir de uma focalização interventiva, que configura toda sua crítica à formação da opinião pública

Vide Ronaldes de Souza. A geopoética de Euclides da Cunha. Em www.casaeuclidiana. org.br. 
nacional via os meios de comunicação. Estes encontraram as explicações para os sucessos dos sertanejos guerrilheiros que bateram três expedições do exército.

\section{Exageramos?}

Deletreemos ao acaso, qualquer jornal daqueles dias. (CUNHA, ibid., p. 314)

A cena tem um forte componente visual, como se o autor pegasse diante de uma câmera os jornais citados (Gazeta de notícias, O país, O Estado de São Paulo) e convidasse o leitor a ler com ele: deletreemos, isto é, leiamos letra por letra, quase soletrando, para não haver dúvidas. O metadiscurso marca a progressão dos pontos de vista nas notícias deletreadas, e informa como os jornais recompunham o objeto de referência, marcando a atitude de comunicação entre esses destinadores jornalistas e seu público leitor, na formação da opinião para salvar a República.

Euclides da Cunha exerceu uma influência na imprensa posterior a suas atividades, como correspondente de guerra, não só pelos seus conteúdos e realismo, mas pelas descrições que faz de um movimento camponês, trazendo para a cena nacional classes subalternas de um mundo rural. Essa novidade gerou igualmente uma escrita jornalística baseada na função estética que busca a expressividade do texto no tratamento de elementos realistas e científicos. Por outro lado, o escritor não cessou de criar sua metáfora da página como um espaço perigoso, como um espaço onde o acontecimento é construído capaz de atingir, e mesmo de persuadir, os variados grupos de leitores que iam sendo afetados por enunciados de opinião repetidos sob vários ângulos acerca de uma eventual conspiração monárquica por parte dos conselheiristas.

Em sua página problematizada, Euclides avança sua prática metalingüística que vai marcando a progressão dos pontos de vista nas notícias deletreadas, e informa como ia sendo recomposto o objeto de referência. Doutrinava-se... Concluía-se... Explicava-se... Afirmava-se... E assim por diante. Esta prática marca a atitude de comunicação entre esses destinadores jornalistas e seu público leitor, a instalação da controvérsia: A opinião nacional esbatia-se de tal modo na imprensa. Na imprensa e nas ruas.

No mesmo movimento, Euclides, na parte Rua do Ouvidor vs Caatingas, nega e ironiza os enunciados como repetição do refrão de uma toada: A mesma toada em tudo. Em tudo a obsessão do espantalho monárquico. Ele 
registra como a toada conduz a um acordo parcial de opinião, que já começa a gerar atitudes. O povo assina uma moção incisiva:

O povo do Rio de Janeiro, reunido em meeting e ciente do doloroso revés das armas legais nos sertões da Bahia, tomadas pela caudilhagem monárquica, e congregado em torno do governo, aplaudindo todos os atos de energia cívica que praticar pela desafronta do exército e da Pátria, aguarda, ansioso, a sufocação da revolta. (CUNHA, ibid, p. 315)

Ele mostra a formação do juízo de opinião que orienta atitudes e determina comportamentos balizados pelo acordo consensual. O presidente da República quebrou sua serenidade habitual:

Sabemos que, por detrás dos fanáticos de Canudos, trabalha a política. Mas nós estamos preparados, tendo todos os meios para vencer, seja como for contra quem for (CUNHA, ibid, p. 315).

Ele demonstra enfim as contradições que iam sendo criadas na associação entre Canudos e os jornais monarquistas do Rio, Gazeta da Tarde, Liberdade e Apóstolo, que foram danificados, todos sendo queimados, por uma multidão aos gritos de Viva a República, conforme noticiou o Jornal do Brasil.

Efetivamente, Euclides, em Os sertões, mostra como se mistifica, se expropria e se explora a opinião de um povo para se obter um resultado, que longe de atender a interesses coletivos, satisfaz objetivos privados. Nesse metadiscurso da formação da opinião que prepara a quarta expedição, é necessário observar ainda as relações guerra/tecnologia, guerra/informação. Mattelard (1994) associa a lógica das guerras ao desenvolvimento das redes de comunicação à distância. O emprego do telégrafo para fins estratégicos tinha mostrado, em várias ocasiões, sua capacidade para a ocupação e a colonização de diferentes territórios, como a Argélia (1842), por exemplo. Em 1854, apareciam as primeiras linhas de telégrafo elétrico que os Estados Unidos iriam aperfeiçoar no momento da guerra da Criméia ${ }^{8}$.

8 Segundo Mattelart $(1994,20)$, outro efeito de armas do telégrafo elétrico foi a guerra de Secessão dos estados Unidos, entre 1861 e 1865. O conflito estimulou a construção da rede de comunicação em quatro anos, $24.150 \mathrm{~km}$ e mais de 6,5 milhões de telegramas. Por outro lado, a guerra da Criméia lançou as bases de uma nova jurisprudência em matéria 
Evidentemente, no Brasil, o evento descrito em Os sertões, materializa as relações conflito/informação cujos contornos Euclides ia delineando:

$\mathrm{E}$ as linhas do telégrafo transmitiam ao país inteiro o prelúdio da guerra sertaneja. (CUNHA, ibid, p. 212)

Euclides registrou não apenas o avanço das redes de comunicação no país, mas igualmente a vanguarda dos meios de locomoção, em que o trem figurava como o modelo da renovação democrática dos transportes. O telégrafo rompia fronteiras para os fluxos de informação, a estrada de ferro vinha reconhecer os limites rígidos das nações e modificar a estratégia da guerra em que as tropas não mais esperavam o inimigo em fortes, mas se deslocavam pelo interior dos países. Naturalmente, o trem, como um atributo do novo poderio militar, representava a conquista e a apropriação do território brasileiro, e Euclides novamente enfatizou a relação guerra/engenharia dos transportes.

Fervilhavam planos gerais, idéias raras, incomparáveis. Engenheiros ilustres apresentavam o traçado de um milagre da Engenharia - uma estrada de ferro de Vila-Nova a Monte-Santo, saltando por cima da Itiúba, e feita em trinta dias, e rompendo de chofre, triunfantemente, num coro estrugidor de locomotivas acesas, pelo sertão bravio dentro.

É que estava em jogo, em Canudos, a sorte da República. (CUNHA, ibid, p. 212)

A mística do trem, como controle do tempo e do espaço, suscitou os mais audaciosos planos e projetos. Mas o que o escritor designou de ficção geográfica ilustra, mais uma vez, a contradição das duas nacionalidades que estavam se enfrentando sem se conhecerem, outra ficção que se coadunou com a ficção política da República em perigo.

A estrada de Monte-Santo enflava, inflexa, pelas chapadas fora, ladeada, em começo, por uma outra que demarcavam os postes da linha telegráfica recentemente estabelecida.

de censura da informação em tempo de guerra. Pela primeira vez, na história da mídia moderna, imagens eram censuradas. 
A linha férrea corre no lado oposto. Aquele liame do progresso passa, porém, por ali, inútil, sem atenuar sequer a caráter genuinamente roceiro do arraial. Salta-se do trem: transpõe-se poucas centenas de metros entre casas deprimidas; e topa-se para logo, à fímbria da praça - o sertão...

Está-se no ponto de tangência de duas sociedades, de todo alheias uma à outra. $O$ vaqueiro encourado emerge da caatinga, rompe entre a casaria desgraciosa, $e$ estaca o campeão junto aos trilhos, em que passam vertiginosamente, os patrícios do litoral, que o não conhecem.

(...) Sentiam-se fora do Brasil. A separação social completa dilatava a distância geográfica; criava a sensação nostálgica de longo afastamento da pátria. (CUNHA, ibid, p. 440-441).

É significativo que o espaço dimensional - com cada um de seus personagens, o vaqueiro e o soldado no cavalo de ferro - tenha encaminhado a formação de metáforas ambientais litoral versus sertão - como definidoras de dois estilos de vida incompatíveis. Se Euclides buscou a unidade nacional na raça, na disciplina, no comportamento e no meio, neste instante, ele chegou à afirmação categórica desta inviabilidade. Foi o momento da divisão radical das duas sociedades distinguíveis por signos diametralmente opostos: cavalos/trilhos, casas deprimidas, desgraciosas/ cidades da costa.

Neste registro temático, é absolutamente importante notar o desenvolvimento das tecnologias, como índice de um progresso que evoluiria, daí pra frente, lado a lado com a construção da informação e a formação de uma opinião dita de massa que, nesse caso, e na lógica narrativa euclidiana, exerceu a função de verdadeira antagonista das duas sociedades, se constituindo no legítimo bárbaro inimigo.

\section{Bases de teorias da comunicação e da formação de opinião}

Essas páginas que trouxeram a emoção e a tragicidade de uma guerra construída cujos resultados formavam uma narrativa tão improvável na qual o futuro não acreditaria, tem influências também na literatura do século XX, com a abordagem dos problemas do Brasil profundo, e com a emergência de narrativas híbridas que representam seus enunciados narrativos e suas próprias formas de enunciar. $\mathrm{O}$ diálogo entre ficção e comunicação não deixa de existir em todas as obras do ciclo canudiano ${ }^{9}$ em que a figura do

9 Vide, como exemplo, A guerra do fim do mundo (1981) de Mário Vargas Llosa, A casca da serpente (1989), de José J. Veiga, As meninas de Belo Monte (1993), de Júlio Chiavenatto, A quinta expedição (2002), de Oleone Fontes, O Veredito de Canudos (2001), do 
jornalista dinamiza e explica as tramas narrativas. Afinal, Euclides tomando consciência do poder de uma página, pediu distância, afastamento para fechar Os sertões, para virar a página, para que pudéssemos buscar com ele mais adiante, sobre essa página sempre trágica, uma série de atitudes que instaura pactos de leitura e solicita cumplicidades complexas.

Em todo ciclo canudiano, pode-se encontrar os pressupostos do Novo Historicismo em que as narrativas históricas, que recontam os fatos passados, empreendem um ato interpretativo que mostra a História sob novos ângulos. Esses novos ângulos são destinados a mostrar a vida cotidiana de pessoas simples e vencidas que participaram da história, ao invés de ilustrar apenas os atos heróicos dos grandes vencedores. Dessa forma, o ato de transformar o passado em história capta a cultura específica, que habita o cotidiano desses novos atores históricos, aliado a um ato poético apto a estetizar o universo representado. A cultura sertaneja não é revelada, em suas origens medievais de uma Península Ibérica ocupada por Mouros, nas formas em que foi transculturada pelos antigos colonizadores, nas obras de Euclides? A língua portuguesa sertaneja, nos repentes, nas festas, nos cateretês e sapateados, nos aboios e nas relações com a natureza, não é aí apresentada?

Euclides da Cunha lança mão de um léxico apurado para tratar da terra brasileira, produzindo um consórcio produtivo entre arte e ciência. Recorre a formas híbridas de composição para mostrar a rica vida cultural dos sertanejos, fazendo alianças fundamentais para o futuro da literatura brasileira entre língua erudita e língua popular. Esse hibridismo estilístico se evidencia igualmente produtivo para a prática jornalística de todo século $\mathrm{XX}$ através do qual a militância política toma novos rumos estéticos com o desenvolvimento das crônicas.

Muitos estudiosos já abordaram a utilização dos verbos de movimento que revelam a forma viva da terra, tanto em seu em-si, quanto como adjuvante dos nativos nas lutas contra forças militares, em todo ciclo canudiano. Mas o que é interessante para ainda ser estudado é a teoria da comunicação, com uma conseqüente teoria da opinião pública, caracterizada ora como opinião nacional, ora como opinião coletiva, que está embutida nas páginas

húngaro Sandor Marai. Vide descrição desses romances no artigo A influência centenária de uma fundação: Os Sertões como a grande narrativa histórica do Brasil, Revista da ANPOLL, vol. 16. 
da obra euclidiana. Euclides problematizou as atitudes dos formadores de opinião no momento em que se dão conta de que um confronto com uma página branca pode gerar um processo de significação suscetível de dar forma a argumentos eivados de valores libertadores ou opressores para uma dada sociedade. Então, esse projeto comunicacional do ciclo canudiano, fundado por Euclides, tem por objeto não os significados, mas a significação, isto é, um conjunto de relações responsáveis pelo sentido dos textos que são produzidos pelos ajustamentos entre produção e recepção.

O risco da comunicação é fundamental nos chamados homenspalavra de todo o ciclo que abre espaços para se refletir sobre a própria formação da escrita: Eu escrevia esses adjetivos e acreditava neles ${ }^{10}$. Ao mesmo tempo, é uma reflexão sobre a forma de se perceber o homemoutro, a outra nacionalidade, aquele que ainda não se enquadrou na civilização brasileira, e continua espelhando o Brasil profundo em suas tradições, mesmo existindo em meio natural inóspito, com injustiças sociais. Euclides iniciou essa consciência estética de promover, no conjunto de sua obra, uma dessimetria relacional de grande distancia no reconhecimento da produção de sua própria escrita. A série de discursos posteriores que atravessaria a série de obras sobre Canudos, com investimento neo-realista, neo-histórico, maravilhoso ${ }^{11}$, fantástico ${ }^{12}$, seria responsável por registrar o impacto da obra fundadora de Euclides, o que ela traz de novo para o conhecimento da sociedade, o que ela interpreta de discursos já produzidos sobre o sertão, enfim, o que ela mostra de novo em termos de produção lingüística para a representação de culturas desconhecidas do Brasil profundo.

\section{Referências Bibliográficas}

HUTCHEON, Linda, Poética do pós-modernismo. História. Teoria. Ficção. Tradução de Ricardo Cruz. Rio de Janeiro: Imago, 1991.

MATTELART, Armand. Comunicação Mundo. Petrópolis, VOZES, 1994.

SOUZA, Licia S., Conselheiro e Riel, resistência sertaneja e mestiça no Novo

\footnotetext{
${ }^{10}$ Como se exprime o jornalista míope, que é uma metáfora do jornalista Pimenta da Cunha, em A guerra do fim do mondo.

${ }^{11}$ A casca da serpente.

${ }^{12}$ As meninas de Belo Monte.
} 
Mundo como configurações identitárias. Canadart IX, Revista do Núcleo de Estudos Canadenses, 2001a, p. 75-84.

SOUZA, Licia S., A influência centenária de uma fundação: Os Sertões como a grande narrativa histórica do Brasil. Revista da ANPOLL, vol. 16, São Paulo, 2004a, p. 147-182.

WHITE, Hayden, Metahistory: The Historical Imagination in NineteenthCentury Europe. Baltimore: Johns Hopkins UP, 1973.

Romances:

CHIAVENATO, José Júlio. As meninas de Belo Monte. São Paulo, Editora Página Aberta, 1993.

CUNHA, Euclides da. Os Sertões, 21 ${ }^{\mathrm{a}}$. ed., Rio de Janeiro, Ediouro, 2000.

FONTES, Oleone. A Quinta Expedição. Salvador, Ponto e Vírgula, 2002.

VARGAS Llosa. La Guerra del fin del mundo. Barcelona, Editora Seix Barral, 1981.

VEIGA, José J. A Casca da serpente. $2^{\text {a }}$. ed., Rio de Janeiro, Editora Bertrand Brasil, 1989.

Periódicos:

Épico dos sertões faz 110 anos. Oleone Coelho Fontes. A Tarde Cultural, 6-10-2007.

Contato com a realidade faz autor rever conceitos. Licia Soares de Souza. A Tarde Cultural, 6-10-2007.

Nossa Vendéia I. O Estado de São Paulo, julho de 1897.

Sertanejo, mito resistente. Licia Soares de Souza. A Tarde Cultural, 8-10-2005.

Sites:

SOUZA, Ronaldes de Melo. A geopoética de Euclides da Cunha, 2002. Disponível em: http://www.casaeuclidiana.org.br/download/default.asp 
VENTURA, Roberto. Euclides da Cunha e A República. Disponível em: http://www.scielo.br/scielo.php?pid=S0103-40141996000100024\&script= sci_arttext

ZANDONÁ, Deise. Relações controversas: o mito na história segundo a crítica de Hayden White. Disponível em: http://www.historiaehistoria.com. $\mathrm{br} / \mathrm{materia} . \mathrm{cfm} ? \mathrm{tb}=$ alunos\&id $=4$ 